\title{
A HORTA ESCOLAR NUM CONTEXTO DE EDUCAÇÃO ALIMENTAR E NUTRICIONAL EM UMA ESCOLA PÚBLICA
}

\author{
THE SCHOOL GARDEN IN A CONTEXT OF FOOD AND NUTRITIONAL EDUCATION \\ IN A PUBLIC SCHOOL
}

\section{Kelly Cristiane Michalichen ${ }^{a}$, Claudia Brauna ${ }^{b}$, Rosângela Aparecida Ribas Fernandesc, Mariana Abe Vicente Cavagnarid}

akellymichalichen25@gmail.com, bclaudiabrauna@outlook.com, crofernandes83@hotmail.com, dmarianaav@hotmail.com Universidade Estadual do Centro-Oeste - Guarapuava (PR), Brasil

Data de recebimento do artigo: 25/08/2017

Data de aceite do artigo: 19/09/2017

\section{RESUMO}

Introdução: As hortas escolares fazem parte das estratégias para melhorar a qualidade alimentar e nutricional dos escolares. Materiais e métodos: Foram realizadas atividades de educação alimentar e nutricional (EAN) no contexto de consumo e cultivo de hortaliças. Durante as açôes de EAN, foram aplicados dois questionários para avaliar o consumo de hortaliças, sendo um pregresso à ação e outro posterior à atividade para verificar o conhecimento adquirido segundo os conteúdos expostos. Resultados: Participaram do estudo 30 alunos, com média de 7,4 anos de idade, sendo 14 (46,6\%) do gênero feminino e 16 (53,3\%) do gênero masculino. Com relação às hortaliças mais consumidas, destacaram-se a alface, o repolho, o tomate e o brócolis. Quanto à frequência de consumo, verificou-se que 46,6\% dos alunos consomem diariamente alguma hortaliça. Não foram identificadas associaçôes entre frequência do consumo de hortaliças e estado nutricional. Conclusóes: As crianças apresentaram bom conhecimento sobre EAN no contexto do consumo de hortaliças, porém apresentaram baixo consumo delas. Assim, sugere-se mais estratégias nutricionais a fim de incentivar e acompanhar o consumo de hortaliças, visto que a escola pode auxiliar na otimizaçáo do consumo desse importante grupo de alimentos para o desenvolvimento de escolares.

Palavras-chave: Comportamento alimentar; educação nutricional e alimentar; estado nutricional.

\section{ABSTRACT}

Introduction: School gardens are part of strategies to improve the dietary and nutritional quality of schoolchildren. Materials and methods: Food and nutrition education activities related to the consumption and cultivation of vegetables were carried out. During the EAN actions, two questionnaires were applied to evaluate the consumption of vegetables: one was a pre-action, the other was subsequent to the activity to verify the knowledge acquired according to the exposed contents. Results: Thirty students (mean age of 7.4 years) participated in the study, 14 (46.6\%) were female and $16(53.3 \%)$ were male. The most consumed vegetables were lettuce, cabbage, tomato, and broccoli. Regarding the frequency of consumption, it was verified that $46.6 \%$ of the students consume daily some vegetables. There were no associations between the frequency of consumption of vegetables and nutritional status. Conclusions: The children presented a good knowledge about food and nutrition education in the context of the consumption of vegetables, but they also presented low consumption of them. Thus, it is suggested more nutritional strategies in order to encourage and monitor the consumption of vegetables, as the school can help in the optimization of the consumption of this important food group for the development of schoolchildren.

Keywords: Feeding behavior; food and nutrition education; nutritional status. 


\section{Introdução}

A obesidade infantil é considerada um dos problemas de saúde pública mais alarmantes, haja vista as futuras consequências da doença na vida adulta. A Pesquisa de Orçamento Familiar do Instituto Brasileiro de Geografia e Estatística 2008-2009 apontou que uma em cada três crianças, de 5 a 9 anos, estava acima do peso recomendado pela Organização Mundial da Saúde (OMS) ${ }^{1}$.

Para deter e reverter a obesidade infantil, uma série de açóes na área de saúde pública têm intensificado esforços para melhorar a qualidade nutricional dos escolares através do estabelecimento de políticas ou práticas institucionais que promovam açóes favoráveis para a adoção de uma alimentação melhor. Essas práticas incluem diversas estratégias e abordagens complementares, como açóes de educação nutricional para aumentar a seleção de estudantes a alimentos saudáveis, influenciando positivamente a ingestáo dietética dos aluno ${ }^{2}$.

$\mathrm{O}$ melhor reflexo da ingestão dietética do grupo infantil é o que seus pais e familiares consomem ${ }^{3}$. Assim, hábitos alimentares parentais adequados podem moldar a disponibilidade e acessibilidade a vários alimentos ${ }^{4}$, repercutindo consequentemente em uma alimentação adequada. Entretanto, a escola também possui papel fundamental na promoção de hábitos alimentares saudáveis, como a inserção de alimentos como frutas e hortaliças nas refeiçōes diárias dos escolares, conforme recomenda a $\mathrm{OMS}^{5}$.

Dessa forma, as hortas escolares ganham destaque como um contribuinte de saúde pública ${ }^{6}$, pois possuem grande potencial para auxiliar na promoção da atividade física, bem como numa ingestão dietética adequada, favorecendo um equilíbrio energético apropriado ${ }^{7,8}$. O consumo de hortaliças em crianças é universalmente reduzido ${ }^{9-11}$, sendo esses vegetais o grupo de alimentos mais comumente rejeitados ${ }^{12}$, e isso acontece também dentro da própria categoria, ocorrendo variaçóes em hortaliças específicas, dependendo de suas propriedades sensoriais ${ }^{13}$.

Com isso, o envolvimento das crianças na horta é um tipo de intervenção que possui como potencial aumentar a ingestâo desse grupo alimentar, contribuindo para a adesão de uma rotina adequada em relação à alimentação ${ }^{14}$

Diante do exposto, este trabalhou buscou, através da atividade de educação alimentar e nutricional (EAN) na horta da escola, unir a teoria e a prática de forma contextualizada, auxiliando no processo de ensino aprendizagem e na promoção da saúde.

\section{Materiais e metodologia}

Este estudo tem caráter transversal e prospectivo e foi aprovado pelo Comitê de Ética em Pesquisa (Comep) da Universidade Estadual do Centro-Oeste (número de parecer 1.971.957)

A pesquisa ocorreu no período em que as acadêmicas realizavam estágio curricular na área social, especificadamente no âmbito escolar, durante o mês de maio de 2017.

Utilizou-se como critério de inclusão crianças de 7 a 9 anos de idade, de ambos os gêneros, as quais estavam matriculadas no $3^{\circ}$ ano B da Escola Municipal Carlita Guimarães Pupo e que já participavam das atividades da horta.

Antes da realização da educação nutricional, foi entregue aos alunos um questionário de frequência alimentar sobre hortaliças. Esse questionário continha questôes simples com respostas múltiplas e fechadas, definidas em sete categorias: nunca, menos de uma vez por semana, uma a três vezes por mês, uma vez por semana, duas a quatro vezes por semana, uma vez por dia e duas ou mais vezes por dia - lembrando que o questionário apresentava as mesmas opçóes para todas as hortaliças, a fim de se analisar os hábitos alimentares dos escolares em relaçáo ao grupo alimentar pesquisado.

Após a aplicação do questionário de frequência alimentar sobre hortaliças, foram expostos, através de fundamentos teóricos: o que é nutrição, a importância de uma alimentação saudável, o que são os nutrientes e quais as suas funçóes, evidenciando principalmente as vitaminas e os minerais. Ressaltou-se a influência do consumo de hortaliças para a saúde principalmente para essa faixa etária (cujos integrantes estão em fase de crescimento e de formação dos hábitos alimentares), com o objetivo de causar admiraçáo por parte dos alunos sobre os problemas relacionados à falta de ingestáo de hortaliças, de modo que eles pudessem estabelecer como hábito diário a ingestão desse grupo alimentar em quantidades adequadas.

Além disso, foram abordados os conceitos de vegetal, de hortaliça (condimentar, folhosa, do tipo fruto, do tipo flor, subterrânea e hidropônica), de sistema de produção orgânico e de canteiro. Foram esclarecidas as diferenças entre horta comercial e horta doméstica ou caseira, bem como foi explicado sobre as diferentes épocas de plantio das hortaliças. Também foi enfatizada a importância do cercado ao redor da horta, bem como do reaproveitamento do lixo orgânico, além da vantagem de se possuir uma horta.

Logo após a exposição do conteúdo teórico, foi realizada a atividade prática com os alunos, na qual eles foram direcionados da sala de aula até a horta, e então, eles observaram todos os aspectos da horta, como o funcionamento 
do sistema de hidroponia, quais hortaliças condimentares estavam sendo cultivadas na horta, e se estavam presentes ou não hortaliças subterrâneas, folhosas, hortaliças-fruto e hortaliças-flor, dentre outros aspectos da horta.

Posteriormente, os alunos foram organizados em fila, receberam sementes de beterraba-chata do Egito, cenoura do tipo Danvers meio comprida, couve-brócolos Piracicaba precoce e rabanete-saxa, e foram conduzidos ao local correto de plantio. Logo depois de plantarem as sementes, cada aluno recebeu uma muda diferente (variando entre: alface-americana, couve-flor, couve-manteiga e repolho-roxo), e foi feita a orientação quanto ao local do plantio. Foram utilizados quatro canteiros para as sementes e um canteiro para as mudas.

No momento seguinte, com o auxílio das acadêmicas, os alunos regaram suas respectivas sementes e mudas com dois regadores de plástico.

Ao final, foi aplicado um questionário para avaliar o conhecimento adquirido dos alunos em relação às açôes desenvolvidas (Quadro 1), no qual constavam oito questóes, cada uma com duas alternativas, sendo que os alunos deveriam assinalar um $\mathrm{X}$ na alternativa que estivesse correta. Toda a ação realizada demandou cerca de uma hora e meia.

Quadro 1: Questionário de avaliação do conhecimento adquirido

1) Marque a alternativa que diz o que sáo hortaliças:

( ) Toda planta pequena plantada em hortas

( ) Toda planta grande plantada em horta

2) Marque a alternativa que diz o que são verduras:

( ) Plantas que possuem várias cores

( ) Plantas que possuem a cor verde

3) Marque a alternativa que dá exemplo do que são hortaliças condimentares:

( ) Cebolinha, salsinha e orégano

( ) Batata, cenoura e alface

4) Marque a alternativa que dá exemplo do que sáo hortaliças folhosas:

( ) Brócolis e berinjela

( ) Alface e rúcula

5) Marque a alternativa que dá exemplos de hortaliças que são subterrâneas:

( ) Tomate e pepino

( ) Cenoura e mandioca

6) Marque a alternativa que dá exemplos de hortaliças-flor:

( ) Cenoura e couve-flor

( ) Couve-flor e brócolis

7) Marque a alternativa que dá exemplos de hortaliças-fruto:

( ) Tomate e chuchu

( ) Alface e abobrinha

8) Marque a alternativa que diz o que sáo hortaliça hidropônicas:

( ) Hortaliças cultivadas na água

( ) Hortaliças cultivadas na terra

Fonte: Elaborado pelos autores, 2017.
Foi inclusa no estudo a avaliaçáo do estado nutricional dos indivíduos que participaram da atividade. Como método, foi utilizada a avaliação antropométrica, que é considerada um bom indicador, de fácil aplicação, confiável, de baixo custo e não invasiva ${ }^{15,16}$, a qual foi realizada utilizando as medidas de peso e estatura. Para a variável peso, o equipamento utilizado foi uma balança portátil digital (da marca Britânia), com capacidade de até $150 \mathrm{~kg}$, a qual foi colocada em uma superfície plana em uma sala reservada. As crianças estavam descalças, com o mínimo possível de roupa, sendo orientadas a pisarem no centro da balança. Para aferição da estatura, foi utilizada uma fita métrica, colocada em uma parede lisa, a qual não continha rodapé, para que não influenciasse no resultado. Os alunos foram orientados a permanecerem descalços, posicionando-se com os calcanhares e o corpo o mais próximo da parede. Posteriormente, realizamos o cálculo de Índice de Massa Corporal (IMC), analisando também mais duas variáveis: idade e gênero. Em seguida, houve classificação de acordo com os parâmetros recomendados pela Organização Mundial da Saúde ${ }^{17}$, levando em consideraçáo que os gráficos de percentis são diferentes para gênero masculino e feminino.

Para análise dos dados, foi elaborada uma planilha no Excel contendo as seguintes variáveis: nome do aluno, gênero, frequência de consumo de cada alimento, escala referida, número de acertos e erros referente a cada questão do questionário de conhecimento adquirido e estado nutricional.

Com relaçâo ao questionário de frequência alimentar de hortaliças, a análise dos dados foi realizada da seguinte forma: para avaliar percentual de consumo, atribuiu-se escalas a cada categoria, sendo Escala 1 (nunca), Escala 2 (menos de uma vez por semana), Escala 3 (uma a três vezes por mês), Escala 4 (uma vez por semana), Escala 5 (duas a quatro vezes por semana), Escala 6 (uma vez por dia) e Escala 7 (duas ou mais vezes por dia), levando em conta a maior escala assinalada. Para análise da ordem de maior frequência de hortaliça, consideramos o alimento que apresentou maior percentual nas Escalas 6 e 7 (consumo diário) e como alimento menos consumido aquele que obteve o percentual de "nunca" mais elevado. Já para avaliar o questionário de conhecimento adquirido, foi calculado o percentual de erros e acertos de cada questáo, bem como o percentual total.

A análise dos dados foi realizada por meio de estatística descritiva, com médias, desvio-padrão, frequências relativas e absolutas.

\section{Resultados e discussão}

Participaram do estudo 30 alunos da faixa etária de 7 a 9 anos de idade, sendo $14(46,6 \%)$ do gênero feminino e $16(53,3 \%)$ do gênero masculino. 
A Tabela 1 apresenta o consumo das diferentes hortaliças segundo as categorias de frequência. As hortaliças mais consumidas diariamente pelos alunos foram a alface, o repolho, o tomate, o brócolis e o pepino, pois apresentaram percentuais de 16,6\% cada uma, enquadrando-se nas categoriais de frequência (uma vez por dia e duas ou mais vezes por dia). Em contraste, a hortaliça avaliada como a menos consumida foi a couve, que obteve percentual de $83,3 \%(n=25)$ como nunca consumida.

Tabela 1: Frequência alimentar de consumo de hortaliças entre escolares

\begin{tabular}{|c|c|c|c|c|c|c|c|}
\hline Hortaliça & Nunca & $\begin{array}{l}<1 \mathrm{vez} \\
\text { por semana }\end{array}$ & $\begin{array}{l}1 \text { a } 3 \text { vezes } \\
\text { por mês }\end{array}$ & $\begin{array}{l}1 \mathrm{vez} \\
\text { por semana }\end{array}$ & $\begin{array}{l}2 \text { a } 4 \text { vezes } \\
\text { por semana }\end{array}$ & 1 vez por dia & $\begin{array}{l}2 \text { ou mais } \\
\text { vezes por dia }\end{array}$ \\
\hline Alface & $40 \%(n=12)$ & $13,3 \%(n=4)$ & $23,3 \%(n=7)$ & $3,3 \%(n=1)$ & $3,3 \%(n=1)$ & $10 \%(\mathrm{n}=3)$ & $6,6 \%(n=2)$ \\
\hline Repolho & $46,6 \%(n=14)$ & $3,3 \%(n=3)$ & $13,3 \%(n=4)$ & $6,6 \%(n=2)$ & $3,3 \%(n=1)$ & $6,6 \%(n=2)$ & $10 \%(n=3)$ \\
\hline Tomate & $50 \%(\mathrm{n}=15)$ & $10 \%(\mathrm{n}=3)$ & $16,6 \%(n=5)$ & $6,6 \%(n=2)$ & $0 \%(\mathrm{n}=0)$ & $6,6 \%(n=2)$ & $10 \%(n=3)$ \\
\hline Brócolis & $50 \%(n=15)$ & $10 \%(n=3)$ & $6,6 \%(n=2)$ & $10 \%(\mathrm{n}=3)$ & $6,6 \%(n=2)$ & $6,6 \%(n=2)$ & $10 \%(\mathrm{n}=3)$ \\
\hline Cenoura & $56,6 \%(\mathrm{n}=17)$ & $10 \%(\mathrm{n}=3)$ & $13,3 \%(n=4)$ & $13,3 \%(n=4)$ & $0 \%(\mathrm{n}=0)$ & $3,3 \%(\mathrm{n}=1)$ & $3,3 \%(\mathrm{n}=1)$ \\
\hline Pepino & $56,5 \%(\mathrm{n}=17)$ & $10 \%(\mathrm{n}=3)$ & $13,3 \%(n=4)$ & $0 \%(\mathrm{n}=0)$ & $3,3 \%(\mathrm{n}=1)$ & $6,6 \%(n=2)$ & $10 \%(n=3)$ \\
\hline Couve-flor & $63,3 \%(n=19)$ & $13,3 \%(n=4)$ & $6,6 \%(n=2)$ & $3,3 \%(\mathrm{n}=1)$ & $6,6 \%(n=2)$ & $0 \%(\mathrm{n}=0)$ & $6,6 \%(n=2)$ \\
\hline Abobrinha & $66,6 \%(n=20)$ & $13,3 \%(n=4)$ & $10 \%(\mathrm{n}=3)$ & $0 \%(\mathrm{n}=0)$ & $3,3 \%(n=1)$ & $0 \%(n=0)$ & $6,6 \%(n=2)$ \\
\hline Beterraba & $66,6 \%(n=20)$ & $13,3 \%(n=4)$ & $6,6 \%(n=2)$ & $10 \%(\mathrm{n}=3)$ & $0 \%(\mathrm{n}=0)$ & $3,3 \%(n=1)$ & $0 \%(n=0)$ \\
\hline Chuchu & $70 \%(\mathrm{n}=21)$ & $10 \%(\mathrm{n}=3)$ & $0 \%(n=0)$ & $10 \%(\mathrm{n}=3)$ & $3,3 \%(n=1)$ & $3,3 \%(n=1)$ & $3,3 \%(\mathrm{n}=1)$ \\
\hline Abóbora & $73,3 \%(\mathrm{n}=22)$ & $10 \%(\mathrm{n}=3)$ & $6,6 \%(n=2)$ & $3,3 \%(\mathrm{n}=1)$ & $0 \%(\mathrm{n}=0)$ & $3,3 \%(n=1)$ & $3,3 \%(\mathrm{n}=1)$ \\
\hline Agriāo/Rúcula & $76,6 \%(n=23)$ & $6,6 \%(n=2)$ & $6,6 \%(n=2)$ & $6,6 \%(n=2)$ & $3,3 \%(\mathrm{n}=1)$ & $0 \%(\mathrm{n}=0)$ & $0 \%(n=0)$ \\
\hline Couve & $83,3 \%(n=25)$ & $3,3 \%(n=1)$ & $0 \%(\mathrm{n}=0)$ & $6,6 \%(n=2)$ & $0 \%(\mathrm{n}=0)$ & $3,3 \%(\mathrm{n}=1)$ & $3,3 \%(n=1)$ \\
\hline
\end{tabular}

Fonte: Elaborada pelos autores, 2017.

Costa et al. ${ }^{18}$ realizaram um estudo para avaliar o consumo alimentar de escolares de acordo com os grupos presentes na pirâmide alimentar. Com relação ao grupo das hortaliças, eles apresentaram resultados parecidos com os deste estudo, observando que as hortaliças mais consumidas e de maior preferência entre os escolares foram a alface, o tomate, o repolho, a cenoura e o pepino.
Outro estudo demonstrou que dentre as hortaliças preferidas pelas crianças, encontravam-se a alface $21,4 \%(n=24)$, a cenoura $15,2 \%(n=17)$, o tomate 13,4\% ( $\mathrm{n}=15)$, e o brócolis 6,3\% $(\mathrm{n}=7)^{19}$.

De acordo com a Pesquisa Nacional de Saúde no Brasil - PNS (2013), o percentual de pessoas de 18 anos ou mais de idade que consumiam cinco porções diárias de hortaliças foi de $37,3 \%$, variando entre $28,2 \%$ na 
regiāo Nordeste, $42,8 \%$ na região Sudeste e 43,9\% na região Centro-Oeste. As mulheres (39,4\%), em média, consumiam mais esses alimentos que os homens $(34,8 \%)$. Notou-se, que o consumo de frutas e hortaliças mostrava aumento com a idade e com o grau de escolaridade.

Com esses dados, percebe-se um baixo consumo de hortaliças pela população brasileira em geral, o que coloca o Brasil em situação bastante desfavorável em comparação com as estimativas de países desenvolvidos. Além do mais, como já exposto, o melhor reflexo da ingestão dietética do grupo infantil é o que seus pais e familiares consomem, mas como apresentado pelos estudos, as crianças muitas vezes são negligenciadas pelos próprios responsáveis, o que contribui para a formação de hábitos alimentares inadequados, repercutindo de forma negativa na saúde.

Além da atenção familiar, a população infantil merece especial atenção das políticas públicas preventivas, pois as transformaçóes do comportamento alimentar, influenciadas pelo contexto socioeconômico e cultural, têm grande efeito sobre a saúde desses indivíduos, tornando-os vulneráveis a inúmeras patologias.

O espaço escolar apresenta-se como importante local para o desenvolvimento de programas de educação e saúde, incluindo a educação nutricional, pois é dentro da escola que o estudante permanece por um grande período, estabelecendo suas primeiras interaçóes e relaçóes sociais, participando de experiências que possam influenciar seus hábitos alimentares. E os processos educacionais precisam ser ativos, lúdicos e interativos, favorecendo mudanças de atitudes e das práticas alimentares. Além disso, a implementação de açóes nos hábitos alimentares deve ser ampla à família e à comunidade escolar, para que os resultados sejam atingidos e perdurem por longo tempo.

Com relação à frequência alimentar de hortaliças, após serem definidas as escalas (Figura 1), nota-se que houve maior percentual de crianças que consomem hortaliças duas ou mais vezes por dia (Escala 7), num total de 33,3\% ( $\mathrm{n}=10)$. As que consomem hortaliças somente uma vez ao dia (Escala 6) alcançaram percentual de $13,3 \%(n=4)$. Para o grupo que consome hortaliças de duas a quatro vezes na semana (Escala 5), uma vez por semana (Escala 4) e de uma a três vezes por mês (Escala 3), os percentuais foram similares, resultando em 6,6\% $(\mathrm{n}=2)$. Os que consomem hortaliças em menos de uma vez por semana (Escala 2) obtiveram 3,3\% ( $\mathrm{n}=1)$. Aqueles que não consomem hortaliças (Escala 1) apresentaram percentual de $30 \%(n=9)$.

Figura 1: Classificação da frequência de consumo de hortaliças

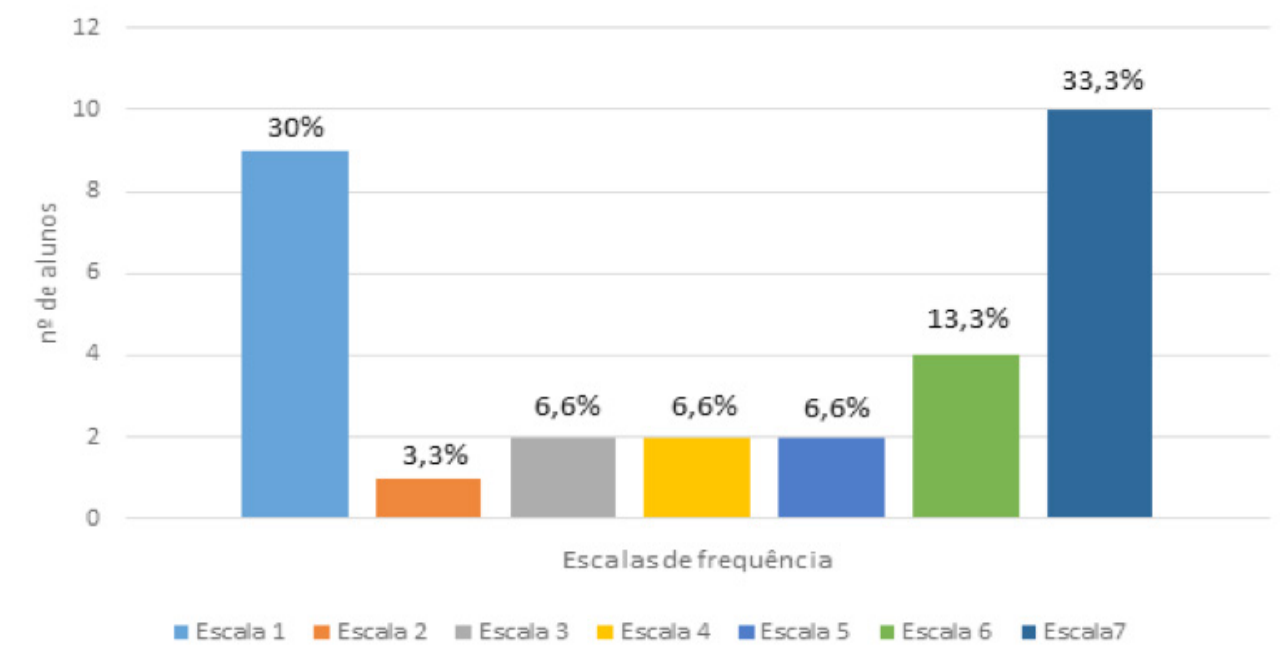

Fonte: Elaborada pelos autores, 2017.

Dessa maneira, observa-se que apenas 46,6\% (Escala 6 e 7) da amostra relatam consumo diário de alguma hortaliça, evidenciando que há baixo consumo entre eles, pois o restante, $53,3 \%$, não consomem hortaliças sequer uma vez por dia, náo alcançando assim as recomendaçóes diárias de vitaminas e minerais que são fornecidas pelo consumo deste grupo de alimentos.
Quanto ao questionário de conhecimentos adquiridos, observa-se (Tabela 2) que houve dificuldade por parte dos avaliados nas questôes $3 \mathrm{e} 7$, pois apresentaram maiores percentuais de erros do que acertos. Entende-se que houve baixo conhecimento a respeito de hortaliças condimentares e hortaliças-fruto, pois o percentual de acertos foi de $43,3 \%$ e $46,6 \%$, correspondendo a menos da metade da turma. 
Tabela 2: Acertos e erros referentes aos questionários sobre o consumo de hortaliças entre escolares

\begin{tabular}{|c|c|c|}
\hline Perguntas & Acertos & Erros \\
\hline $\begin{array}{l}\text { Marque a alternativa que } \\
\text { diz o que são hortaliças. }\end{array}$ & $86,6 \%(n=26)$ & $13,3 \%(\mathrm{n}=4)$ \\
\hline $\begin{array}{l}\text { Marque a alternativa que } \\
\text { diz o que são verduras. }\end{array}$ & $86,6 \%(n=26)$ & $13,3 \%(n=4)$ \\
\hline $\begin{array}{l}\text { Marque a alternativa que } \\
\text { dá exemplo do que são } \\
\text { hortaliças condimentares. }\end{array}$ & $43,3 \%(n=13)$ & $56,6 \%(n=17)$ \\
\hline $\begin{array}{l}\text { Marque a alternativa que } \\
\text { dá exemplo do que são } \\
\text { hortaliças folhosas. }\end{array}$ & $76,6 \%(n=23)$ & $23,3 \%(\mathrm{n}=7)$ \\
\hline $\begin{array}{l}\text { Marque a alternativa que } \\
\text { dá exemplos de hortaliças } \\
\text { que são subterrâneas. }\end{array}$ & $66,6 \%(n=20)$ & $33,3 \%(n=10)$ \\
\hline $\begin{array}{l}\text { Marque a alternativa } \\
\text { que dá exemplos de } \\
\text { hortaliças-flor. }\end{array}$ & $66,6 \%(n=20)$ & $33,3 \%(n=10)$ \\
\hline $\begin{array}{l}\text { Marque a alternativa } \\
\text { que dá exemplos de } \\
\text { hortaliças-fruto. }\end{array}$ & $46,6 \%(n=14)$ & $53,3 \%(n=16)$ \\
\hline $\begin{array}{l}\text { Marque a alternativa que } \\
\text { diz o que são hortaliças } \\
\text { hidropônicas. }\end{array}$ & $60 \%(\mathrm{n}=18)$ & $40 \%(n=12)$ \\
\hline
\end{tabular}

Fonte: Elaborada pelos autores, 2017.

A respeito da avaliação total de acertos e erros, nota-se que o conhecimento dos alunos sobre hortaliças é relativamente bom, pois verificou-se maior prevalência de acertos $68,75 \%(\mathrm{n}=165)$, subentendendo-se que eles adquiriram conhecimentos com a atividade proposta.

Com relação ao estado nutricional dos alunos, $63,3 \%$ $(\mathrm{n}=19)$ deles se encontravam com IMC adequado ou eutróficos (valores entre percentil 3 e 85), 16,6\% $(n=5)$, em sobrepeso (valores entre percentil 85 e 97), e $20 \%$ $(n=6)$, em obesidade (valores acima do percentil 97).

As prevalências de sobrepeso e obesidade no sexo feminino foram, respectivamente, de $6,6 \%$ e $10 \%$, e no sexo masculino, de $10 \%$ e $10 \%$, demostrando-se poucas diferenças em relação ao sobrepeso e similaridade em relação à obesidade.

O estudo de Bertin et al. ${ }^{15}$ demonstra que há relação entre estado nutricional e conhecimentos sobre nutrição, numa percepção de que os piores conhecimentos ocorreram em maior proporção nas crianças obesas $(15,1 \%)$. Porém, em nosso estudo, o conhecimento que as crianças tinham e/ou adquiriram sobre hortaliças não teve relação direta com seu estado nutricional, pois tanto crianças com menor número de acertos se enquadravam no diagnóstico de eutrofia ou IMC adequado como crianças com número de acertos igual a zero encontravam-se acima do peso.
Outra variável analisada foi estado nutricional $x$ consumo de hortaliças, a qual não apresentou grau de significância, não havendo interaçóes entre as variáveis.

Este estudo apresentou algumas limitações muito comuns que ocorrem quando se aplica um inquérito alimentar. Visto que o público alvo era composto por crianças, optou-se pelo método mais simples para avaliar o consumo alimentar, sendo assim, envolvem-se questóes de falhas de memória do participante, sub ou superestimação do seu consumo e influências externas, não sendo possível análise da ingestão de nutrientes de forma específica. Desta forma, vale ressaltar a escassez de estudos que avaliam o consumo alimentar de crianças e adolescentes, havendo dificuldade na comparação de resultados.

\section{Conclusão}

Identificou-se que as crianças avaliadas revelaram bons conhecimentos em nutriçấo e a maioria delas também estava com bom estado nutricional, porém apresentou baixo consumo diário de hortaliças. Em relação à EAN aplicada aos alunos, obteve-se grande proveito, pois as crianças já apresentavam certo conhecimento em relação ao grupo das hortaliças e se encontravam bastante ativas e animadas em toda a aplicação da ação nutricional.

Dessa forma, é preciso que haja relação entre conhecimento, hábito alimentar e estado nutricional, para que assim seja promovido uma melhor qualidade de vida. Sugere-se que as intervenções realizadas no âmbito nutricional devam ser muito mais do que apenas oferecer conhecimentos, elas precisam integrar saúde, escola e família.

\section{Referências}

1. Cruz CS, Silva CH. Obesidade infantil: análise sobre a produção científica brasileira no Scielo. Anais do $16^{\circ}$ Encontro Nacional de Pesquisa em Ciência da Informação; 2015, João Pessoa, Brasil. João Pessoa: UFPB; 2015.

2. Institute of Medicine. School meals: building blocks for healthy children. Washington, DC: National Academies; 2010.

3. Bere E, Klepp KI. Correlates of fruit and vegetable intake among Norwegian schoolchildren: parental and self-reports. Public Health Nutr. 2004;7(8):991-8.

4. Baranowski T, Cullen KW, Baranowski J. Psychosocial correlates of dietary intake: advancing dietary intervention. Annu Rev Nutr. 1999;19(1):17-40.

5. Pearson N, Biddle SJ, Gorely T. Family correlates of fruit and vegetable consumption in children and adolescents: a systematic review. Public Health Nutr. 2009;12(2):267-83. 
6. World Health Organization. WHO fruit and vegetable promotion initiative: report of the meeting, Geneva, 25-27 August 2003. Geneva: WHO; 2003.

7. Hill J, Peters J, 1998. Environmental contributions to the obesity epidemic. Science. 1998;280(5368):1371-4.

8. Wells NM, Ashdown S, Davies E, Cowett F, Yang Y. Environment, design and obesity. Environ Behav. 2007;39(1):6-33.

9. Krølner R, Rasmussen M, Brug J, Klepp, KI, Wind M, Due P. Determinants of fruit and vegetable consumption among children and adolescents: a review of the literature. Part II: qualitative studies. Int J Behav Nutr Phys Act. 2011;8:1-38.

10. Lynch C, Kristjansdottir AG, Te Velde SJ, Lien N, Roos E, Thorsdottir I, et al. Fruit and vegetable consumption in a sample of 11-year-old children in ten European countries: the Pro Greens cross-sectional survey. Public Health Nutr. 2014;17(11):2436-44.

11. Blissett J, Fogel A. Intrinsic and extrinsic influences on children's acceptance of new foods. Physiol Behav. 2013;121:89-95.

12. Cooke L, Carnell S, Wardle J. Food neophobia and mealtime food consumption in 4-5 year old children. Int J Behav Nutr Phys Act. 2006;3:1-6.
13. Reed DR, Tanaka T, McDaniel AH. Diverse tastes: genetics of sweet and bitter perception. Physiol Behav. 2006;88(3):215-26.

14. Hutchinson J, Christian MS, Evans CEL, Nykjaer C, Hancock N, Cade JE. Evaluation of the impact of school gardening interventions on children's knowledge of and attitudes towards fruit and vegetables: a cluster randomised controlled trial. Appetite. 2015;91:405-14.

15. Bertin RL, Malkowski J, Zutter LCI, Ulbrich AZ. Estado nutricional, hábitos alimentares e conhecimentos de nutrição em escolares. Rev Paul Pediatr. 2010;28(3):303-8.

16. Eckert RG, Silva JMP, Rodrigues VC. Avaliação antropométrica e dietética de professores, funcionários e colaboradores de uma escola privada de Cascavel, Paraná. Anais do $1^{\circ}$ Seminário Internacional de Ciência, Tecnologia e Ambiente; 2009, Cascavel, Brasil. Cascavel: Unioeste; 2009.

17. World Health Organization. Growth reference 5-19 years [Internet]. 2007 [citado em 2017 maio 13]. Disponível em: $<$ https://goo.gl/JiNZC>.

18. Costa MCD, Cordoni Júnior LC, Matsuo T. Hábito alimentar de escolares adolescentes de um município do oeste do Paraná. Rev Nutr. 2007;20(5):461-71.

19. Naves MLA. O impacto da educação alimentar e nutricional no reconhecimento e consume de frutas e hortaliças entre alunos de uma escola pública do Distrito Federal [monografia]. Brasília, DF: Universidade de Brasília; 2014.

\section{Como citar este artigo:}

Michalichen KC, Brauna C, Fernandes RAR, Cavagnari MAV. A horta escolar num contexto de educação alimentar e nutricional em uma escola pública. Rev. Aten. Saúde. 2018;16(55):14-20. 